\title{
An Exploration of Muhammadu Bukhari's Socio-Political Cognition through Stylistic
}

\author{
Analysis \\ * Dr. Aisha Farid, Assistant Professor \\ ** Madiha Saeed, Assistant Professor (Corresponding Author) \\ *** Dr. Muhammad Sabboor Hussain, Assistant Professor
}

\begin{abstract}
Political discourse is a recent but increasingly exciting field of study. The political discourse offers much scope for interdisciplinary research. This current study is a stylistic analysis of the Inaugural speech delivered by Nigerian President Muhammadu Bukhari in Abuja on $29^{\text {th }}$ May 2015. The current study aims to signify the role of Stylistics in CDA to unleash socio-political cognition in speeches. This qualitative research owing to its interdisciplinary nature draws on stylistics and critical discourse analysis as well. Teun A. Van Dijk's socio-cognitive approach is used to analyze the mental models underlying linguistic structures made explicit through stylistic analysis. The stylistic analysis is conducted on lexical and grammatical levels, but cohesion and speech acts have also been highlighted in the findings and discussion part. The study explores how stylistic devices are used to create a rhetorical effect and how this effect qualifies for being persuasive. The stylistic analysis reconnoiters the linguistic patterns, and CDA leads to the ideologies that shape these patterns. This study strengthens the belief that both stylistics and critical discourse analysis have great scope and power in revealing discursive practices of hegemony and persuasion.
\end{abstract}

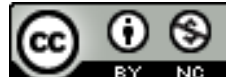

Keywords: Stylistics, Style, Political Discourse, Critical Discourse Analys is, Socio-cognitive Approach

\section{Introduction}

A language is a powerful tool that is used to hide as much as it reveals. The dynamics of language use are quite similar to the dynamics of power. The last two decades have seen a tremendous increase in the amount of attention paid to language ideologies. Language is acknowledged as an integral part of social processes, and language studies offer a comprehensively broad field for research. Though the linguists may happily ascribe equality to all languages as their potential of meaning-making is concerned. Nevertheless, all the languages do not enjoy the same status in richness and wider acceptability. "This differentiation is not random but is the result of particular processes under specific social, political, cultural and economic conditions" (Milan and Johnson, 2010). This differentiation leads to the assumption that language use is heavily invested with social, ethical, moral, and political considerations. The linguistic patterns explicate a phenomenon more complex than just sending out and receiving information, and this also happens to be the chief end of stylistic analysis. The present study attempts to delineate multi-faceted functions of language in political discourse, especially in the speeches from specialized offices as that of the President. Muhammadu Bukhari: the Nigerian President's inaugural speech displays his social and political identity. This combo of identities made explicit through stylistic analysis is of paramount interest for the researcher in tracing the socio-political cognition at work.

Muhammadu Bukhari was born in 1942 in Nigeria. He was the twenty-third child of a tribal chieftain. He became an army general and overthrew the government in an army coup in 1983. He ruled $\mathrm{Nigeria}$ as a dictator for a couple of years and afterward chose to take the democratic turn. He contested for presidency in 2003, 2007, and 2011 but remained unsuccessful. The pitiable condition of national affairs made him win the presidential election of 2015. In the reign of preceding president Goodluck Jonathan, the country faced many problems like Boko Haram, Niger Delta, unemployment, and many others, which find a detailed expression in his inaugural speech. The country considered

\footnotetext{
* Department of English, GC Women University Sialkot, Pakistan Email: aishafarid@gcwus.edu.pk ** Department of English, GC Women University, Sialkot, Pakistan Email: madiha.saeed@gcwus.edu.pk *** Department of English, GC Women University, Sialkot, Pakistan Email: rajasaboor@hotmail.com
} 
Bukhari their only hope and took his election campaign as a preamble of the much-awaited change. The speech under consideration is a reassurance of all those commitments which were a part of his manifesto. His speech's detailed analysis brings to the surface all the unique patterns used by him to create a rhetorical effect.

\section{Objectives of the study}

The current study aims

1. To find out the linguistic patterns and stylistic devices used by Bukhari.

2. To develop a link between content and context through the objective analysis of these patterns and devices.

3. To trace nuances of the cognitive component of discourse.

\section{Research Questions}

This analytical study attempts to provide answers to the following questions.

1. What are the stylistic devices used by Bukhari in his inaugural speech as President?

2. How do these devices explicate the Macro structures of political discourse?

3. How far is Bukhari's socio-political cognition a reason behind the discourse patterns produced by him in his speech?

\section{Lite rature Review}

Widdowson (1975, p:3) defines stylistics as the study of literary discourse from a linguistic orientation. Stylistics for him is empirical and scientific that approves and investigates the content based on linguistic evidence. Stylistics is the thorough study of textual analys is in which the foremost consideration is given to language (Simpson, 2004). It gives various interpretations of the text along with a better insight into the style of the author. Stylistics as a method demands objectivity rather than personal perceptions and subjective interpretations. Aims in stylistics can only be achieved when one has basic comprehensions of all peculiarities of general linguistics (DeVito, 1967). Though stylistics is not limited to literary texts only, stylistic analys is of literature helps understand the language (Akyel, 1995). According to Widdowson (2014), Stylistics is a medium to relate other subjects and disciplines, and in itself, it is not autonomous. Likewise, it links language with literature. Stylistics aims to provide a deeper insight into the text to support or explore the linguistic examination.

Style's meaning and perception vary from person to person. According to Carter (1989), style relies typically on linguistic levels. Adejare (1992) further elaborates it when he pointed out that style is an unclear term. Lawal (1997), however, defines style as a dimension of language that talks about lexical choices, phrases, clauses, and sentences that are reliable and harmonious with the topic they are dealing with. Style, then, is the process of making choices from the available reservoir of language, picking what is suitable, and leaving what is not required. Prasannata Ramtirthe (2017) categorizes style into these divisions: 1. Style as choice 2. Style as deviation 3. Style as situation 4. Style as the temporal phenomenon 5. Style is individual. These all are stylistic domains, but this current article focuses on the second and third divisions. The situation, in the words of Ramtirthe, refers "to the context in which the text comes to life. The situation could be social, cultural, political or pragmatic"(pg. 4). The context used here in this study is that of a political situation.

The specifications which make a discourse political are many. The classification of a speech or discourse as political has primarily been related to its actors or authors, who are essentially politic ians and more so by the discursive properties innate to the speech (Jacob Anderson, 2014). Van Dijk (2013) affirms that any effort to define political discourse would be futile if it does not incorporate politics. He strongly asserts that political discourse involves the actor, action, and event and the political system, processes, relations, and ideologies. Here, the critical discourse analysis finds its most fruitful ventures in political discourses. John Flowerdew (2013) considers Critical Discourse Analysis a transdisciplinary approach to analys is in line with French Linguist Michel Foucault and those of Critical linguists. Critical discourse analysts' primary aim is to deconstruct the structures of discourse with small 'd' (linguistic features) to lay bare the discourse structures with a capital 'D' (ideology). The major concern of an analyst then is to locate the sources of these ideologies. Social cognition and mental schemata propounded by Van Dijk $(1993,1995)$ may be one of the answers. Blommaert (20025) finds it quite interesting how these social cognitive patterns find the ir way into human cognition and result in well-crafted ideologies. It can now be said that Stylistics and sociocognitive approaches to discourse are instrumental in establishing links among text, context, and conviction. 
These links within the text reveal a thinking mind's workings conducting and supervising the discursive practices to achieve specific goals. Political discourses have been a critical realm of linguistic analysis due to the scope it offers to researchers. The reason for this extraordinary scope is the complex human activity that deserves critical study, mainly because of its central place in the organization and management of society (Dylgjeri: 20). Political jargons are used to exercise influence to shape public consciousness. The political discourse analysis educates the analysts about mind play and the tangible devices used to regulate society's mind and opinion in general. Political speeches become instrumental in laying bare how social cognition is structured through political cognition by creating and sustaining social associations, articulating social and national emotions, and vending philosophies, policies, and political missions in any society.

\section{Research Methodology}

The current study is qualitative. The research dimensions are descriptive and analytical. The sample of the study is the inaugural speech delivered by the Nigerian President in 2015. Since it comes from a specialized politician, so the domain of this research is political discourse. An eclectic approach is adopted for analysis. The selected discourse structures are identified at the micro-level outlined by Van Dijk by using Leech and Short Checklist (2007). Though this checklist explores several linguistic and stylistic categories, the analys is was conducted on lexical and grammatical levels for the sake of delimitation. The Macro structures which connect the content with context were investigated using Van Dijk's socio-cognitive model of critical discourse analysis. This model helps investigate a communicative event as a set of three mechanisms: Discourse component, cognition component, and social component. Shafaat Hussain (2015), quoting Van Dijk, asserts that the "Socio-cognitive approach focuses on the dialectical re lationships between social structure and cognition in discourse." This approach should be employed carefully to an individual's cognition because it can have ideological underpinnings in reproducing inequitable discourses and social structure.

\section{Ideology}

(Macro-Structure)

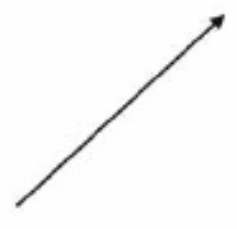

Socio-cognitive, historical processes of interpretation; Decoding

\section{Discursive processes of Production;} Encoding
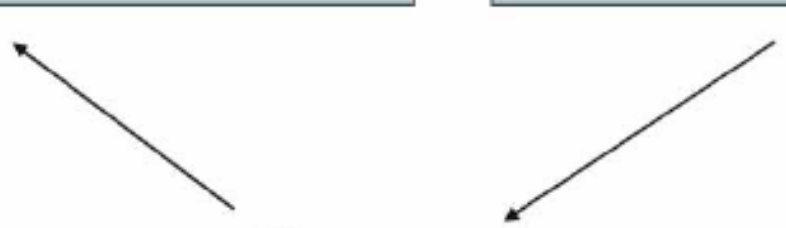

\section{Discourse}

\section{(Microstructures)}

Van Dijk (2016) puts forward that discourse structures are connected to social structures through a complex cognitive interface. This interface is cognizant of the immediate context and the context at large. The knowledge achieved through personal experiences and social interactions influences the production of discourse and is affected by other available discourses simultaneously, which he calls intertextuality. Van Dijk (discourse and knowledge) asserts that knowledge has a role to play in the actions required from language use. The knowledge here is the shared knowledge of an epistemic community which helps in getting the information across.

According to Van Dijk, this context model emphasizes the importance of Speech Acts, which are performed well when based on social cognition. Austin (1962), in his book 'How to Do Things with Words,' and Searle $(1969,1975,1976)$, with his work on 'speech acts', considered that every utterance has a function to perform. Both Searle and Austin classified these utterances into different categories based on their functions. This research followed the five significant categories provided by Searle. These divisions are representatives, directives, commissive, expressive and declarative. Austin 
(1962) talked about the felicity condition, which is the same as social cognition. Austin believed that the participants involved in a communicative event must know the language, and they must be serious about the event. Political speeches are delivered with specific intentions, which can only be achieved if the speaker and the audience have a shared social and universal context. Speech Acts, therefore, have been investigated to authenticate the analysis.

Data Analysis (Dis course Components)

The speech is analyzed linguistically using Leech and Short (2007) Checklist on the following significant and sub- levels.

\section{Lexical Level}

Noun: The speech contains almost every variety of nouns: common, proper, abstract, and concrete nouns.

Table 1

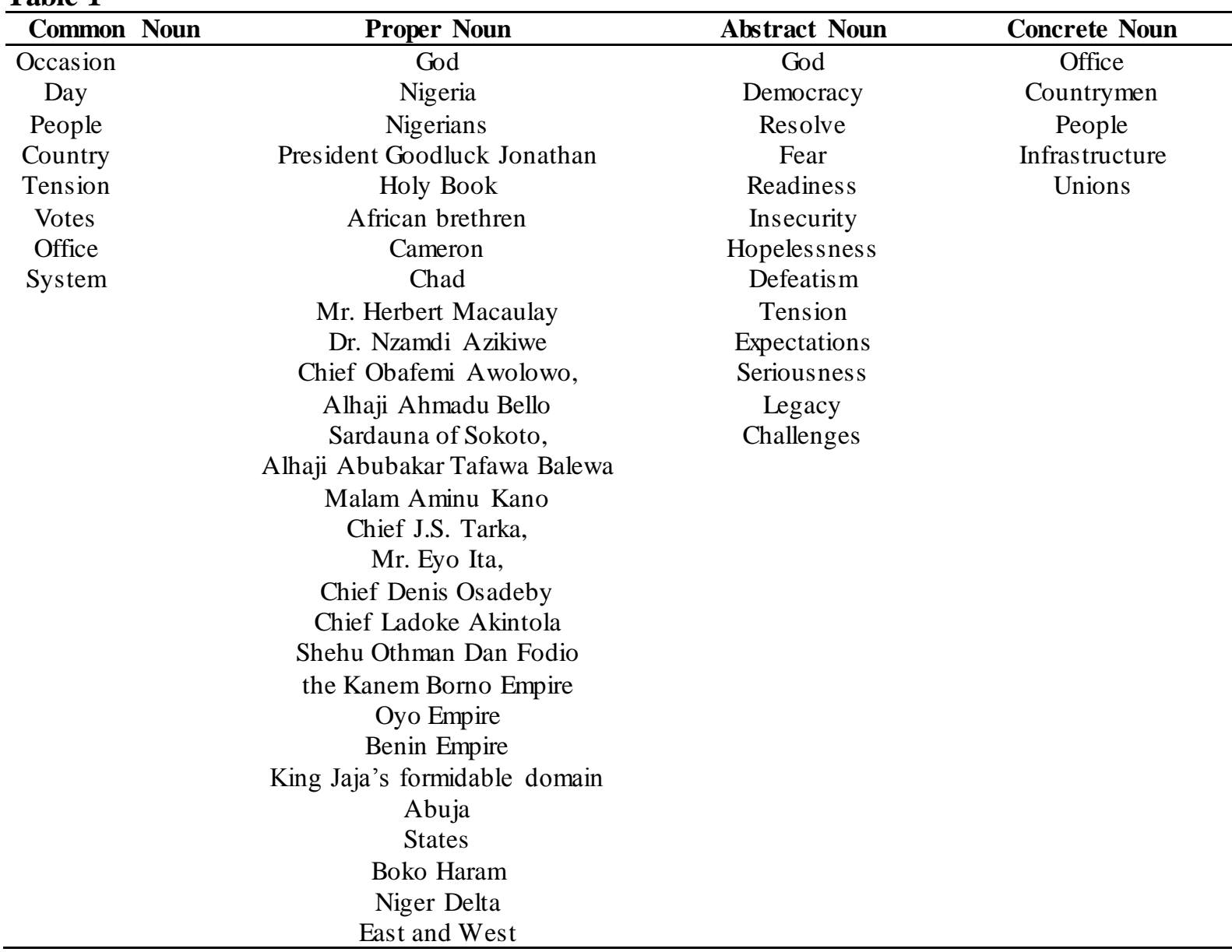

Pronouns: Bukhari makes extensive use of personal pronouns. In a speech of one thousand and nine hundred and two words, the pronoun "I' has been used twenty-two times, whereas the pronoun "We" is used thirty-three times. Other pronouns like you, he, them and their, have also been used, but they are few and far between.

Table 2

\begin{tabular}{l}
\hline Pronouns \\
\hline Frequency \\
Adjectives: The use of adjectives adds flavor to public speaking, and this speech is no exception. The \\
speaker has made rich use of adjectives. The adjectives are analyzed on four levels: \\
Attributive: these are the adjectives that precede the noun they modify. The speaker has made much \\
use of this type of adjectives. A few examples are strong support, elected government, our people, \\
long hours, hot sunshine, democratic culture, African Brethren, spoilt children, great civilization, \\
and so on. \\
Predicative: these are the adjectives that are placed after the noun they modify. Though these have \\
also been used in the speech, they are less in number than attributive adjectives. A few examples are: \\
"our journey has not been easy," "these fears are groundless,""... when the cause seemed hopeless".
\end{tabular}


Intensified: these adjectives intensify the meaning, e.g., more effective, more serviceable.

Superlative degrees: Sometimes, the suffixes are added to generate the comparative and superlative degrees of adjectives like 'quickest' and 'safest' as found in the speech. However, these degrees can be generated by adding an adverb to the adjective. The examples from the speech are: 'the most vibrant, 'the most immediate, and 'the most effective way.'

Though all the types mentioned above can be identified in the speech, the attributive adjectives exceed all the rest as far as the occurrence is concerned.

Verb: Much of the tempo of a spoken or written discourse is carried in the verbs used. The following different types of verbs are identified in the political discourse under discussion.

Action verbs: Also known as dynamic verbs, these words denote the subject's physical and mental actions.

Stative Verbs: These are the verbs that denote situations rather than actions. These include thoughts and feelings.

Infinitives: These are essentially the primary forms of verbs preceded by 'To.' Here, 'to' is not used as a preposition but as a part of the verb itself.

Table 3

\begin{tabular}{lll}
\hline Action & Stative & Infinitive \\
\hline Shown & Hope & To Witness \\
Thank & Become & To celebrate \\
Cooperate & Believed & To entrench \\
Stay & Seemed & To cooperate \\
Count & Wish & To play \\
Sworn & Think & To Unite \\
\hline
\end{tabular}

Modal Verb: The vital role of modal verbs in a sentence is to communicate the capacity, possibility, suggestion, or determination. The most frequent modal verbs used in this speech are 'will' and 'can.' Other modal verbs are either scarce or none at all.

Table 4

\begin{tabular}{llllllll}
\hline Modal Verb & Will & Can & Must & Have to & Should & May & Might \\
\hline Frequency & 19 & 11 & 04 & 04 & 03 & 01 & 01
\end{tabular}

Adverb: Adverbs add to the meaning of a verb, adjective, or another adverb. Adverbs are usually classified into four categories of manner, time, place, and frequency. The speech under consideration is rich in adverbs, but most of these turn out to be the adverbs of manner, which, of course, contribute to the thematic underpinnings. A few evidences from the text are: 'consciously', 'expeditiously', 'with dispatch', 'constitutionally', 'optimally', 'alike', 'alive', 'heavily', 'strongly', 'abroad', 'newly ele cted' etc.

Grammatical Level

Sentences:

The speaker uses a matrix of simple, compound, and complex sentences, but Bukhari's overall sentence structure is complex. In this ninety-two sentences long speech, the shortest sentence is only four words long like: the past is prologue whereas the longest sentence is fifty words long: With depleted foreign reserves, falling oil prices, leakages, and debts, the Nigerian economy is in deep trouble and will require careful management to bring it round and to tackle the immediate challenges confronting us, namely, Boko Haram, the Niger Delta situation, the power shortages and unemployment especially among young people.

Much of the complexity of sentences are created by the coordinating conjunction 'And': Nigerians have shown their commitment to democracy and are determined to entrench its culture . The connecting word 'and' has been used ninety-two times to create cohesion and thematic flow. Another deviation is identified where the sentences start with prepositions: 'At home, we face....', 'In recent times Nigerian leaders...', 'For now, the armed forces will be fully charged...'

Noun Phrases:

The speech is replete with noun phrases ranging from plain modifiers to extended complex constructions like: 'truly democratically elected government', 'wider international community, 'viable and progressive country', 'legislative and judicial arms of government', 'an eccentric and unorthodox preacher, 'friendly and well-compensated security forces', 'mindless, the godless group.' 


\section{Verb Phrases:}

The verb phrases used here refer to the present and future. The phrases like Has preserved, I shall go, We are going to tackle, We shall charge them, represent the speaker's strong commitment.

Paralle lism: The speech has many parallel structures at the word and syntactic levels.

Many sentences and clauses start with the same words:

I would like to thank President...

I would like to thank millions of...

I belong to everybody, and I belong to nobody.

I thank those..., I thank our other..., I thank all of you.

We have to improve the standards of our education. We have to look at...., we have to upgrade our...

Findings and Discussion: (Cognitive and Social Component)

Van Dijk's socio-cognitive model (2015) deals with texts on three levels investigating the cognitive component, the social component, and the discourse component. The micro cognitive structures of personal memory and knowledge find representation in social micro-structures. These micro-level social structures are the interaction and the resultant discourse production of members of society. The study of these micro-levels leads to the analysis of macro-structures of discourse where the shared knowledge and beliefs of groups and society shape the whole community's ideology, norms, and values. Quite interestingly, this approach in Critical Discourse Analysis does not investigate these structures of discourse, cognition, and society as independent components. The integrat ion of all these three components is significant as each of these shapes and is shaped by others simultaneously. This need for integration is an essential trait of Interdisciplinary research. Thus, for each discourse construction, what is needed is a plain description and an explanation of relations between various components. The discourse constructions first need to be described and interpreted in terms of mental models or knowledge as produced or understood by the users of a specific language. These basic cognitive structures then reveal the socio-political underpinning in a specific social context, as is the case with the inaugural political speech of Muhammadu Bukhari.

Muhammadu Bukhari, the incumbent Nigerian President, took over the office in 2015, and the speech under consideration is his inaugural speech. Bukhari, formerly an Army General, had his identity established as a seasoned politician over the years. Ruling the country for a short period (1983-1985) because of an army coup, he, during his election campaign, was accused of suspending the constitution. His campaign, however, was based on the anti-corruption manifesto, and he patiently waited for his democratic turn. He was able to hold office again in 2015. This speech is a true reflection of his political sagacity backed by his knowledge of societal norms, ideologies, and structure. He used language as a tool to connect to his audience to achieve his intended goals. Here, the intentions and the intended effect of his discourse are laid bare, with the socio-cognitive approach. Speech Acts, as they refer to the specific functions that language is supposed to perform, became quite handy in this analys is to access the macro structures of discourse. As it is an inaugural speech, there are commitments and directives intended to bring hope and insurgency.

\section{Cohesion}

Without addressing the audience or other dignitaries present in the ceremony, he directly addresses the general audience. The humble start is indicative of his intentions to make his audience realize that he is acknow ledging the support extended by his party, voters, and supporters. The repetition of ' I am immensely grateful to God....I would like to thank...I would like to thank the million.....I thank our other countrymen .....I thank all of you ..' very rightly connect him to his audience immediately. He, being one of them, knows the Psyche of Nigerians. A lot of proper nouns used by him serve as exophoric references, which generate the same connotations in his mind and the minds of his audience. His references to God and Holy Book are an effort to present himself as a true Muslim. He also expresses the great spirit of forgiveness by declaring that he will not be vindictive towards anyone. He makes much use of anaphoric and cataphoric references as well as a cohesive device: "A few people have privately voiced fears that on coming back to the office I shall go after the m. These fears are groundless". "What is now required is to build on these legacies..."

Bukhari used very long sentences, in which much of the cohesion is attained by using the coordinating conjunction 'and' that was used ninety -two times by him in his speech: "... in the rain and hot sunshine to register and cast their votes and stay all night if necessary to protect and ensure 
their votes count and were counted." The use of this conjunction not only creates cohesion but also force in the argument. It gives out a feeling that there is a lot that he, being a leader, needs to tell his people. It also helps to betray his potentials as an army general capable of providing detailed accounts. Niger Delta and Boko Haram both have been used to create intertextuality. They allude to the most significant threat faced by Nigeria over the past years. He informs his audience how Boko Haram, an eccentric preacher, was turned into a martyr due to his extrajudicial killing by police. He also makes historical references to Nigeria's great civilization, and the role played by their forefathers.

The speech relies heavily on its usage of adjectives for cohesion and coherence. The adjectives create the desired collocations and support the expression as well. Being an inaugural speech, it explicates the existing challenges and the forthcoming bright future of Nigeria. Bukhari made judicious use of this stylistic device to add strength to his argument. The adjectives with positive connotations are used to portray a rosy picture of how well the situation will be and how great the Nigerian civilization will be: great civilization, efficient, disciplined people, responsible and accountable governance. On the other hand, adjectives with negative connotations also find expression to identify the existing problems and challenges: pervasive corruption, spoilt children, depleted fore ign reserves, falling oil prices.

\section{Speech Acts}

The communicative competence of a speaker undoubtedly lies in his linguistic and cohesive choices. All these choices are made to achieve some specific ends in the speaker's mind. Speech acts are the divisions that refer to these ends. In ninety-two sentences long speech, most of Bukhari's statements are commissive and quite apt for an inaugural speech. This is the time to start a new journey, so he makes commitments. These commitments may be new or reiteration of the ones in the political manifesto. Speech Acts indeed betray the intentions of the speaker guided by his social and individual cognition. After having mentioned those who did not vote for him, he makes an assertion: "... I intend to keep my oath and serve as President to all Nigerians". He, with this statement, makes an effort to manipulate the social cognition of his community that they can rely upon him as an unbiased leader.

Most of the statements are commissive, as is indicated by the linguistic choices and illocutionary force: this government will do all it can to rescue them alive (commitment to save Chibok girls); we shall overhaul the rules of engagement (commitment regarding human rights violations). These commissive acts can be identified with the he lp of modal verbs used. It is observed that modal verbs like will and can, which contain surety, have the highest frequency, whereas modal verbs like may and might, which give rise to doubt and uncertainty, have the lowest frequency. The verbs also express the intentions of the speaker. He makes almost equal use of stative and action verbs to get his ideas across. The use of verb phrases expounds the need for action and gives rise to directives e.g., we have to improve the standards of our education, we have to look at the whole field of medicare, we have to upgrade our dilapidated physical infrastructure.

\section{Foregrounding through Rhe torical de vices}

Bukhari has made judicious use of language. He has not used colloquial language. He has, instead, used long and verbose constructions, as is evident from his excessive use of noun phrases. This shows his desire to say more in fewer words. The phrases like truly democratically elected government and an eccentric and unorthodox preacher speak for the power in his expression and the speaker's grip over so many things simultaneously. This excessive use of noun phrases is repeated so regularly that it is identified as a linguistic pattern in the speech. The ninety-two sentences long speech does show deviations as well at the grammatic level. Few sentences start with prepositions like: 'At home, we face enormous challenges..., In recent times, Nigerian leaders...' The reason behind this may be that the President wished to be candid sometimes. This deviation, however, brings to the forethought conveyed in these sentences. Eleven sentences start with prepositions, and one starts with the conjunction 'But.' The speech has a direct start which is usually not observed. The speech, however, restores its decorum towards the end, where Bukhari addresses the excellencies and dignitaries present there.

Repetition at the lexical and syntactic level also adds to the thematic cohesion and thus supports the intended effect. The words like thank, will, shall, can, and, have been repeated many times to emphasize the point of discussion. The paralle lism created at the lexical and syntactic level foregrounds the linguistic patterns used by the speaker. The repeated patterns of gratitude in the opening paragraphs show the humbleness and humility of the speaker. The parallelism like 'we have 
to upgrade; we have to improve, and we have to look' bespeak the speaker's seriousness and a drive to fulfill all his commitments. What appears quite unexpectedly is the quote from Shakespeare's Julius Ceaser. Coming from the President of An African country, this quote has a special place as it carries the same message of motivation as Bukhari wanted to communicate. This quotation was indeed the culmination of his appeals for unity, and immediate action, as this may turn out to be their last chance. The concern to be recorded here is that he could have found something from African indigenous literature, yet he chose from an English writer.

\section{Discussion}

The socio-cognitive approach focuses on exposing the mental representations and revealing that many discourses depend on cognitive notions for their complete understanding, especially those of information, beliefs, or knowledge of partic ipants. Bukhari displays his ideology of believing in and respecting the great predecessors, as this is the context he shares with his epistemic community. He also attaches to his audience by referring to those leaders whom he calls Spoilt children. His speech is full of appreciation for those who voted for him and those who did not vote. The pronouns I and we, most often, have been used inclusively. After having initially created the binary of 'us' (for his voters) and 'them' (for the opposition) through the personal pronouns, Bukhari makes excellent use of an antithes is to influence the social cognition: I belong to everybody, and I belong to nobody. The use of the personal pronoun is not just replacing the noun; these are used here to speak on behalf of a whole nation. The whole nation is taken into the halo of 'us' by Bukhari. He makes references to other countries like States and the wider international community to elucidate his worldwide outreach. Since most of his statements are commissive as suits an inaugural speech, he introduces the enormous challenges. He renews his commitment to addressing these challenges right away in the middle part of the speech. Any public speech aims to persuade and influence the listeners, which yields power to the speaker. Bukhari tries to achieve this end by connecting discourse structure to the structures of social contexts. By alluding to history and literature, Bukhari makes use of intertextuality. The texts resemble each other depending upon the discourse, cognition, and social patterns. There is always a text to refer to due to the interconnected nature of discourses performing in an almost similar context. Bukhari ends his speech with a literary allusion from Shakespeare's Julius Ceaser, where he likens the current situation with the one depicted in these lines:

There is a tide in the affair of men which,

Taken at the flood leads to fortune:

Omitted, all the voyage of their life,

Is bound in shallows and miseries.

He, through these lines, urges Nigerians to act timely. He makes them realize that they cannot lose this lifetime opportunity. Using this rhetoric device, he directs them to hit when the iron is hot, and this is precisely what Bukhari does through this speech.

\section{Conclusion}

The detailed stylistic analysis of Bukhari's speech reveals his political sagacity. He uses such devices to make his people believe in his social identity as one of them and his political identity as an elected President. He aims at achieving social cohesion and togetherness by customizing his speech with extensive use of personal pronouns. He is cognizant of the fact that he is looked upon as the harbinger of a bright future. He, therefore, mentions the most imminent and immediate challenges and states his commitment to addressing them all right away. These findings are reached only with the collaboration of stylistics and critical discourse analysis. The first and foremost aim of stylistics is to identify microstructures of discourse. Discourse analysis, on the other hand, investigates the real-life situations where those linguistic patterns are used. Being sub-branches of Applied Linguistics, both stylistics and critical discourse analysis have a great scope as far as the language in use is concerned. As explored by these two fields of study, language essentially emerges as something functional rather than governed by static rules. It is a matter of choosing features from the available options, and these choices, in turn, reveal discourse, cognition, and discourse structures.

\section{References}

Akyel, A. (1995). Stylistic analysis of poetry: A perspective from an initial training course in TEFL. TESL Canada Journal, 13(1), 63-73.

Anderson, J. (2014). A Stylistic Analysis of Some Selected Political Speeches by John Evans Atta Mills. (M. Phil Thesis) . University of Ghana, Legon. Ghana. 
Austin, J. L. (1962). How to Do Things with Words. New York: Oxford University Press.

Blommaert, J. (2005). Discourse: An introduction. Oxford: Oxford University Press.

DeVito, J. A. (1967). Style and stylistics: An attempt at definition. Quarterly Journal of Speech, 53(3), 248-255.

Dylgjeri A. (2017). Analysis of Speech Acts in Political Speeches. European Journal of Social Sciences Studies, 2 (2), 19-25

Flowerdew, J. (2013). Discourse in English Language Education. Routledge.

Hussain, S. (2015). Critical Discourse Analysis: Demystifying the Fuzziness. The International Journal of Humanities and Social Sciences, 3 (10), 242-249.

Johnson, S. \& Milani, T.M. (2010). Language Ideologies and Media Discourse. Continuum International Publishing Group.

Leech, G., \& Short, M. (2007). Style in fiction: A linguistic introduction to English fictional prose (2nd ed.). London: Longman.

Leech, G. N. (2014). A linguistic guide to English poetry (Vol. 4): Routledge.

Ramtirthe, P. (2017). Style and Stylistics: An Overview. Pune Research World, 1 (4), 1-6.

Searle, J. (1975). Indirect speech acts. In Cole, P. \& Morgan, J. L. (Eds) Syntax and Semantics Volume 3: Speech Acts (pp. 59-82). New York: Academic Press.

Searle, J. (1976). The classification of illocutionary acts. Language and Society, 5, 1-24.

Searle, J. R. (1969). Speech Acts. Cambridge: Cambridge University Press.

Simpson, Paul. (2004). Stylistics: A resource bookfor students: Psychology Press.

Van Dijk, T. A. (1993). Principles of Critical Discourse Analysis. Discourse and Society, 4(2), 24928

Van Dijk, T. A. (2016) Socio-cognitive Discourse Studies, a chapter in Handbook of Discourse Analysis. Routledge.

Van Dijk, T. A. (2014). Discourse and Knowledge. Cambridge University Press. 